\title{
Developing and Using a Toolkit for Cultivating Compassion in Healthcare: An Appreciative Inquiry Approach
}

\author{
Charlotte Ramage \\ University of Brighton, United Kingdom \\ Kathy Curtis \\ University of Bournemouth, United Kingdom \\ Angela Glynn \\ University of Brighton, United Kingdom \\ Julia Montgomery \\ University of Sussex, United Kingdom \\ Elona Hoover \\ University of Brighton, United Kingdom \\ Jane Leng \\ University of Surrey, United Kingdom \\ Claire Martin \\ Brighton and Sussex University Hospitals NHS Trust, United Kingdom \\ Catherine Theodosius \\ University of Brighton, United Kingdom \\ Ann Gallagher \\ University of Surrey, United Kingdom
}

\begin{abstract}
This article describes the process of developing and evaluating a 'cultivating compassionate care' toolkit of evidence-based training resources designed to be cascaded through a 'train-the-trainer' approach in three healthcare organisations in Southern England. The purpose of the project was to develop an awareness of compassion, and to investigate how compassion can be recognised, developed, and sustained within the healthcare workforce. The study was based on appreciative inquiry and a train-the-trainer model, using focus groups to generate evidence-based training tools designed with the staff in the participating organisations. Questionnaires evaluated the first wave of Cultivating Compassion workshops delivered by trainers, while semi-structured interviews and focus groups evaluated the experiences of those using the toolkit. The findings demonstrated that a cultivating compassion toolkit, co-created with the healthcare workforce, can develop confidence in engaging in discourse on the meaning of compassionate care, and provoke a focus on self-compassion and compassion towards colleagues. Thematic analysis of interviews and focus group data with participants involved in cascading the toolkit activities revealed the value and usability of the toolkit resource, and the leadership factors influencing its implementation. We conclude that cultivating compassionate practices requires leadership to clearly articulate their values and vision for compassion, ensuring these are clearly supported and integrated throughout the organisation as part of changing culture and practices to support
\end{abstract}


compassionate care. The limitation of the study was that we were unable, due to the project timeline, to measure impact of the project on patients, their families, and carers.

\section{Keywords: appreciative inquiry; compassion; healthcare workforce; train-the-trainer}

${ }^{*}$ Corresponding Author: Charlotte Ramage, School of Health Sciences, College of Life, Health and

Physical Sciences, University of Brighton, Eastbourne BN20 7UR United Kingdom

Email:c.m.ramage@brighton.ac.uk

Journal URL: http://e-learning.coventry.ac.uk/ojs/index.php/pblh

Ramage, C., Curtis, K., Glynn, A., Montgomery, J., Hoover, E., Leng, J., Martin, C., Theodosius, C., and Gallagher, A. (2017) 'Developing and Using a Toolkit for Cultivating Compassion in Healthcare: An Appreciative Inquiry Approach'. International Journal of Practice-based Learning in Health and Social Care, $5(1), 42-64$

\section{(c) $(\$) \ominus$}

BY nc No (C 2017 Charlotte Ramage, Kathy Curtis, Angela Glynn, Julia Montgomery, Elona Hoover, Jane Leng, Claire Martin, Catherine Theodosius, Ann Gallagher. This Open Access article is distributed under the terms of the Creative Commons Attribution Attribution-Non-Commercial No Derivatives 4.0 International License (https://creativecommons.org/licenses/by-nc-nd/4.0/), which permits unrestricted noncommercial use, distribution, and reproduction in any medium, provided the original work is properly cited and is unaltered. 


\section{Introduction}

This article describes the process of developing and evaluating a toolkit of evidence-based resources to cultivate compassionate practice in three healthcare organisations in Southern England. The Cultivating Compassion Project was developed in response to a call for bids from Health Education Kent Surrey \& Sussex (HEEKSS) to provide 'compassion awareness training'. The one-year funded project bid arose from a Secretary of State mandate to Health Education England to deliver 'high quality, effective, compassionate care' (Department of Health 2013). This mandate was triggered by the serious failings detailed in the Mid Staffordshire Francis Report (Francis, 2013) which, amongst its recommendations, outlined the need for a fundamental change of culture in the health care service that placed the patient at the foremost of care decisions. The report also recommended improved support for compassionate caring and committed care through stronger leadership at all levels in the organisation reflecting the values of the NHS Constitution (Department of Health 2015: principle 3):

Respect, dignity, compassion and care should be at the core of how patients and staff are treated not only because that is the right thing to do but because patient safety, experience and outcomes are all improved when staff are valued, empowered and supported.

The project was cognisant of the tension in delivering on a compassion-training mandate (Department of Health 2013) at a time when healthcare staff morale was severely diminished following intense and sustained negative media reports after the publication of the Mid Staffordshire report (Francis 2013). In order to manage the tensions, the project design was driven by an appreciative inquiry methodology and a 'train-the-trainer' model that recognised the good practice and indicators of compassion already in place as the starting point for the project. Central to the methodology was recognition of the expertise within the participants as a resource for cascading developments to their colleagues through a train-the-trainer approach. The toolkit design was iterative and thereby responded to early feedback from train-the-trainer workshops and project team members representing the participating healthcare organisations in a mental healthcare trust, an acute hospital trust, and a large trauma acute hospital trust. The aim was to promote culture change within the workplace through the development of educational tools that could be used by trainers in a range of ways to stimulate and cultivate compassionate practice with their workplace colleagues. The project team were mindful that, within the timespan of the project, it would be difficult to measure the impact of the project on patient safety and care; however, patient safety was at the forefront of the consultation process in toolkit design and implementation.

\section{Background}

The background to this study predominantly draws on United Kingdom literature due to the seriousness of the findings from the Mid Staffordshire inquiry, which had been ongoing since 2008. The length of this inquiry, with its final report in 2013, stimulated numerous opinion articles and research studies seeking to find meaning from the serious omissions in patient care and to identify ways forward for the National Health Service (NHS) workforce.

The Patient Association (Mullen 2009) and Francis reports (Francis 2010, 2013) highlighted serious omissions in basic patient care, particularly with regard to vulnerable adults. In seeking to understand negligent care, these reports identified a small yet significant number of the healthcare workforce failing to reflect the values expected of those in positions of caring for others and lacking courage to protect those in their care (Francis 2010, 2013, Mullen 2009). The culture of metrics to meet efficiency targets was also identified as possibly causing staff to lose sight of person-centred care (Firth-Cozens and Cornwell 2009, Goodrich and Cornwell 2008) and professional values (Francis 2013). In response to this, there was an increased professional focus on the caring relationship; such as the meaning and importance of compassionate practice (van der Cingel 2014). The circumstances that foster compassionate 
practice, and how professional groups might cultivate compassion, became increasingly important to understand (Cole-King and Gilbert 2011, Crawford et al. 2014) and training staff to be 'more' compassionate became a focus for the UK Department of Health (Department of Health 2012, Department of Health 2013).

Fostering self-compassion became one of the areas identified for supporting compassionate practice (Neff and Pommier 2013). A literature review focused on self-compassion in relation to mindfulness by Raab (2014) identified that mindfulness training could help to develop resilience for the requirements of caring roles - such as compassion - and measured coping with others' suffering. In relation to expressing compassion towards another person, Atkins and Parker (2012) identified that engaging in values-affirmation reminds staff why they care and what they care about beyond themselves. When exploring compassion and the organisation, a number of studies and reports referred to the significance of addressing the strategic role of organisations in cultivating compassionate practice through promoting values-based leadership (Adamson et al. 2012, Crawford at al. 2014, Dewar and Cook 2014, Department of Health 2015, Maben et al. 2012, Youngson 2011).

\section{Aims}

The aims of the Cultivating Compassion project were:

- to co-design and co-evaluate through appreciative inquiry with participants an evidencebased Cultivating Compassion toolkit comprising training resources;

- to support participating staff in the use of the Cultivating Compassion toolkit within their clinical environment through a train-the-trainer approach for the benefit of patient care, individual staff, staff teams, and the working environment and culture.

\section{Literature review}

The focus of the literature review was to inform the construction of the Cultivating Compassion toolkit. We wished to understand what factors might mitigate against the expression of compassion and identify ideas and resources that might help us to develop activities that promoted self-compassion and compassion towards others with the aim of promoting an organisational culture of compassionate caring and committed care (Francis 2013). For a more comprehensive review of the compassion literature in relation to this project, see Curtis et al. (2017)

The word 'compassion' is derived from the Latin com (together with) and pati (to suffer). Compassion might then be defined as 'suffering with'. It is understood to involve emotion, such as empathy or sympathy, and a rational understanding of the suffering that enables identification with it; for example, the ability to deliberately and altruistically participate in another's suffering (von Dietze and Orb 2000). Compassion involves, then, emotion and thought, and results in an action that acknowledges suffering and seeks, where possible, to alleviate it. This suggests that recognition of suffering precedes the feeling and action of compassion. This view is reflected in Cole-King and Gilbert's (2011: 30) definition of compassion as a "sensitivity to the suffering of self and others with a deep commitment to try to alleviate and prevent it".

Compassion is a complex concept influenced by personal qualities, both innate and learned (Irons 2013), alongside many other factors (Curtis, Horton, and Smith 2012). Cole-King and Gilbert (2011), Derbyshire (2014), Dewar and Christley (2013), and Paley (2014) identify that environmental factors present in poor working conditions within health services may challenge the "most dedicated health care professional" (Derbyshire 2014: 889). Some studies indicate value in compassion training as it has the potential to increase altruistic behaviour (Weng et al. 2013), affect change in attitude and caring practices (Herbst, Swengros, and Kinney 2010), and improve empathetic communication skills (Brunero, Lamont, S., and Coates 2010, Richardson, 
Percy, and Hughes 2015). Paley (2014), however, argues that there is little to be gained in empathy, compassion and ethics training without addressing the social conditions that influence the behaviour of staff working in those environments. The work of Maben et al. (2012: 259) supports this view noting: "staff wellbeing is an antecedent rather than a consequence of patient care performance".

Being compassionate towards oneself is positively associated with enhanced feelings of compassion and concern for others, altruism, and forgiveness of others (Neff 2003, Neff and Pommier 2013). Neff (2003: 224) identified "three basic components" to self-compassion: extending kindness and understanding to the self; seeing one's experiences as part of the larger human experience, that we are not on our own; and holding one's painful thoughts and feelings in balanced awareness. This latter 'component' relates to mindfulness, which is defined as a non-judgmental awareness of the present moment (Raab 2014). Mindfulness training has recently become more embedded in health care organisations, recognising its contribution to better relational working and reduced stress through developing resilience. Through mindful raised awareness, people can become more attentive to their surroundings and more likely "to act with principles and compassion" (Epstein 1999: 835).

The ways that compassion manifests itself and is recognised in healthcare practice is important to understand how it might best be fostered. Studies have shown that students, patients, and staff identify kindness and compassion as expressed in 'the little things' (Pearcey 2007), also termed 'relational care' by Maben et al. (2012). Attending to 'the little things' can mean compassionate acts are hard to measure, despite being central to a patient's care experience (Maben et al. 2012). There are also recognised difficulties in articulating compassion because compassion as witnessed and experienced includes factors that are difficult to express (Dewar, Pullin, and Tocheris 2011). Despite this, measures of compassion were developed for the Leadership in Compassionate Care Programme (Adamson et al. 2012). The compassion value statements Dewar, Pullin, and Tocheris (2011) developed, reflected a range of dimensions of compassion in everyday working practices, for example:

We make a point of speaking to relatives to update them with information and ask if they have any questions. We try to do this regularly and find this helps us to develop a relationship with them (Dewar, Pullin, and Tocheris 2011: 37).

Burford et al. (2016) found the use of values-based indicators enabled stakeholders to conceptualise values deeply held in their organisation; they helped to highlight and reinforce best practice, boost morale, and build shared understanding of values. Articulating values has also been found to support a stronger sense of self-worth through individuals gaining understanding of 'who they are' and what they care about (Atkins and Parker 2012).

Another approach to enhancing compassionate practice has been shown in the sharing of stories (White 2014). Digital stories like Patient Voices can stimulate learning and improve healthcare practices (Hardy and Sumner 2014). Digital stories are narratives conveyed through a combination of computer-based tools, "images, music, video clips and narration" (Gazarian 2010: 287). Digital stories can be generated through storytelling circles that enable the participants to explore complex practice experiences, and share and reflect on these experiences together (Kitzinger 1995). Visual images and games can be used in the story circles to help participants to find a language to articulate their story. Group discussion in the storytelling circle encourages questioning and framing of the story to identify the central foundation of the story. This is important as it enables the point of the story to be conveyed in a short snapshot of the experience, distilled down to the essence of its meaning (Lambert 2013). Digital stories like those in Patient Voices can be powerfully conveyed in three minute YouTube clips and can help identify compassion values (Dewar, Pullin, and Tocheris 2011).

Training staff in caring practices using didactic teaching within a workshop or a lecture has been shown to have little or no affect in changing behaviour (Davis et al. 1999). In contrast, tools or toolkits with evidence-based educational material can be effective for knowledge translation into 
practice behaviour (Barac et al. 2014, Davis et al 2003). Barac et al. (2014) conducted a scoping review of various toolkits and found they were useful in sharing knowledge, communicating messages, and changing practice involving diverse audiences. Many of these toolkits, however, lacked an evidence base and robust evaluation of their impact. Despite this, the toolkits that were evaluated did suggest that they were an effective method of knowledge translation.

As sustainability of any change in compassionate practice was an important consideration in this project, it was imperative to develop a 'training' model that the organisations could support once the project had ended. Whilst the evidence behind the choice of 'train-the-trainers' models is limited there was some evidence indicating that this model could cascade changes in behaviour (Levine et al. 2007, McClelland et al. 2002). Levine et al. (2007) found the traditional lecturer style of delivering training was not successful; however they found that toolkits enabled peer-educators to facilitate learning. In the Levine et al. (2007) study, university staff acted in a 'trainer' role for other staff who then cascaded the training to their peers using a purposively designed toolkit. Levine et al. (2007) found a significant increase in self-reported knowledge and attitudes of participants six months after the peer sessions.

For the reasons above, the Cultivating Compassion project adopted a train-the-trainer approach supported with a toolkit of activities and resources inclusive of digital stories, values indicators, and mindfulness designed to cultivate compassion through peers within the workplace as well as within customised workshops.

\section{Design}

\section{Theoretical approach}

An appreciative inquiry approach was identified as most appropriate to underpin the project design and the toolkit of resources and as a philosophy to guide the project team in co-creation through the project process (Hammond 1998). Appreciative inquiry is an approach that can be used within organisations to locate best practice and to bring about change. It requires a move from a problem-orientation to an appreciative stance. It involves "studying, exploring, actively searching out the best and focusing on what is good, strong, already working and being achieved in organisations" (Carter 2006: 50). Appreciative inquiry encourages the use of storytelling in teams or groups around actions and activities that affirm their worth and the source of their success (Cooperrider 2000). As an evaluation approach, appreciative inquiry engages with, and appreciates, the perspectives of all stakeholders, identifies best practice, and provides the opportunity to further enhance services and organisations (Cooperrider et al. 2001). This approach proved to be of central importance in motivating team members to progress the project and engage with the health and social care staff in the partner NHS organisations.

\section{Context}

The Cultivating Compassion project involved a year-long programme of designing an evidencebased toolkit, developing and delivering a train-the-trainer cascade of the toolkit resources in the workplace, and an evaluation of the use of the toolkit resources.

\section{Project team}

Local NHS organisations were contacted at the project proposal stage and were asked for expressions of interest. Three NHS organisations volunteered to participate in the project and were involved in the design and cascading of the toolkit. Senior members of staff from each organisation in education, human resources and research lead roles were invited to the project team and were referred to as organisation project leads. The project team comprised 24 members from three universities including schools of health sciences and a medical school; three NHS organisations, including two acute trusts - one with a trauma centre and one mental 
health trust with community and inpatient provision for those with mental health and learning disabilities; and two lay members volunteering within their roles as health service users. The project team also included administrative support from each NHS organisation to manage recruitment of volunteers to the project and who arranged venues for workshops, interviews, and focus groups. Project team members were responsible for the first wave of train-the-trainer workshops demonstrating and supporting the use of the toolkit of activities, prior to the cascading of activity through organisations by participants recruited to the project.

\section{Methods}

\section{Participants}

Participants in the project were drawn from all staff in the three NHS organisations involved, excepting domestic, portering and catering staff which were managed by independent contractors to the NHS organisation. Participants were recruited for the compassion indicator and digital story focus groups through internal email inviting expressions of interest to the workforce in each organisation. These emails were sent by the participating NHS organisation administrators on the project team and included the focus group information sheet and informed consent form. Those wishing to participate were invited to contact the project research officer. Participants to the first wave of train-the-trainer workshops were similarly recruited through the internal NHS organisation email and were given the project administrator for the organisation as their contact to book a place on a workshop. The project administrators then collated names, roles, and place of work for those attending; and organised a venue for the train-the-trainer workshop.

\section{Ethical considerations}

The project proposal gained approval from the Research Ethics and Governance Committees of the organisations and universities involved. All focus group and semi-structured interview participants were provided with project and informed consent information in advance of, and at the time of, the focus groups and semi-structured interviews.

\section{Toolkit design focus groups}

In order to develop many of the resources within the toolkit, such as the digital stories and the compassion indicators, participants from the three NHS organisations were invited to focus groups. The focus group method enabled participants to explore complex practice experiences and to consider the compassion within them by sharing and reflecting on them together (Kitzinger 1995). For a more detailed outline of the toolkit resources, see Table 2.

\section{Compassion storytelling focus groups}

To develop digital stories, two consecutive storytelling focus groups of four hours each were run in each of the three participating organisations. Participants were recruited through each health care organisation project lead asking for expressions of interest. These storytelling focus groups comprised a mixed group of administrators, radiographers, clinical psychologists, doctors, and nurses. The number of participants from each organisation ranged from three to five. The focus groups mimicked the storytelling circle recommended by Lambert (2013) and two of the project team facilitated these groups. Emphasis throughout was placed on sharing and responding to one another's practice stories to help the participants 'find' their own particular story and discuss with one another what aspect of compassion it represented. The second storytelling focus group centred on shaping the stories, using pseudonyms to protect confidentiality, and identifying images through which to convey the story when digitally reproducing them for the toolkit. The final digital recording of the stories involved volunteer actors from a local theatre group doing the voiceovers in order to protect the confidentiality of participants within their own healthcare organisation. 


\section{Compassion indicator focus groups}

Developing compassion indicators throughout the project was an iterative and participatory process with the aim of developing a locally valid set of statements that would reflect diverse ways in which compassion was understood by participants across the three organisations. Initial compassion indicators had been developed by the project team observing the first storytelling focus groups in the three participating NHS organisations where visual images had been used to create discussion on the meaning and experience of compassion in the workplace. An initial 52 indicators were shared within a first indicator focus group and discussed, critiqued, expanded upon, and prioritised, creating 77 indicators. A second compassion indicator generating focus group was then organised to follow the train-the-trainer workshops in two of the partner organisations, an acute hospital and a mental health NHS trust. This second focus group conflated the indicator set from 77 to 65 indicators. In this focus group, the statements were shortened, positive wording was used, and the participants were asked to view the indicator as a statement of intent, to formulate the indicators using the first person plural, and to look for representation across the themes (see Table 1). Each compassion indicator focus group was 60 minutes in length. The compassion indicators proved to be a useful tool in the workshops to stimulate discussion on the presence of compassion in the workplace. They could be cut up into 65 separate compassion statements and divided between groups to rank them in order of importance and discuss and justify their top three choices. They could be shared out between groups in their theme clusters, and participants could identify the most important indicator and discuss their choice. You could simply present one statement as a power point slide, and ask participants to discuss its meaning in groups and share these discussions. The compassion indicators gave voice to a concept that practitioners themselves said that they simply assumed was inherent in their everyday practice, and through discussion, they were able to critically analyse its value and presence within their own teams and practices, and their own compassionate self-care practices.

Table 1: Compassion Indicator - themes and sample indicators

\begin{tabular}{|l|l|r|l|}
\hline \multicolumn{2}{|l|}{ Compassion Indicators } & $\begin{array}{l}\text { No of } \\
\text { items }\end{array}$ & Sample indicator from each theme \\
\hline Theme 1 & Self-compassion & 4 & $\begin{array}{l}\text { I recognise when I have compassion fatigue and } \\
\text { take appropriate action }\end{array}$ \\
\hline Theme 2 & Supporting each other & 8 & $\begin{array}{l}\text { We are always ready to help colleagues even if we } \\
\text { are busy }\end{array}$ \\
\hline Theme 3 & Leadership & 7 & $\begin{array}{l}\text { We recognise that our own readiness to express } \\
\text { compassionate care influences others }\end{array}$ \\
\hline Theme 4 & Organisational culture & 7 & $\begin{array}{l}\text { Compassion is embedded at all levels of our } \\
\text { organisation, both in service provision and in the } \\
\text { care of its workforce }\end{array}$ \\
\hline Theme 5 & $\begin{array}{l}\text { Balancing competing } \\
\text { demands }\end{array}$ & 7 & $\begin{array}{l}\text { We are flexible and responsive: when the } \\
\text { unexpected arises we find the balance between } \\
\text { being compassionate and remaining organised }\end{array}$ \\
\hline Theme 6 & Person-centred care & 10 & $\begin{array}{l}\text { We know that sometimes being compassionate is } \\
\text { being there; to acknowledge, hold or share pain } \\
\text { even when nobody can alleviate it }\end{array}$ \\
\hline Theme 7 & Being non-judgemental & 4 & $\begin{array}{l}\text { We are flexible and offer different care approaches if } \\
\text { people behave differently from our expectations }\end{array}$ \\
\hline Theme 8 & $\begin{array}{l}\text { Holistic approach to } \\
\text { our work }\end{array}$ & 9 & $\begin{array}{l}\text { When working with patients, our team holds hope } \\
\text { and optimism, providing a vision for people even if } \\
\text { they are not able to have one yet }\end{array}$ \\
\hline Theme 9 & Relating to people & 9 & $\begin{array}{l}\text { We get to know patients as people, recognising } \\
\text { them from one day to the next }\end{array}$ \\
\hline
\end{tabular}




\section{Train-the-trainer model}

To promote sustainability and leadership for cultivating compassion a 'train-the-trainers' model was used supported by the Cultivating Compassion toolkit of resources. The project lead and administrator for each NHS organisation recruited participants to the first two train-the-trainer workshops which were facilitated by members of the project team. The workshops were one whole day in length, and were structured around three compassion circles: compassion towards self, compassion towards others, and organisational compassion. During the latter compassion circle workshop, participants were encouraged to explore how they may engage others in cultivating a compassionate discourse in their sphere of work. The train-the-trainer workshop is outlined in Appendix 1.

During the trainer workshops, digital stories were used to generate discussion and participants were invited to describe and share an act of compassion encountered in their recent practice within small groups and put these on 'post it' notes around the room. It was considered important to focus on the prevalence of compassion in practice rather than its absence as a positive means of generating discussion and encouraging individuals to undertake a role in promoting the project in their practice. The compassion indicators were used to stimulate a discussion on the prevalence of a particular value in practice and factors that might facilitate or hinder its expression which would be concluded with suggestions as to how best to cultivate this compassion value within their own practice. Participants then volunteered as 'trainers' to cascade this training within their organisation. These training activities were designed by the project team as a half-day workshop.

Each participating organisation was offered two further supported half day workshops with the trainers working alongside a member of the project team during the initial cascade of the project in their organisation. Whilst the train-the-trainer workshops and the trainer-supported half day workshops followed a structural design, the message the project team facilitators left the trainers with was that they could customise the workshops using the activities on the Cultivating Compassionate Care WordPress ${ }^{\circledR}$ site to meet their differing staff needs and timelines of availability.

Monthly compassion circle groups were organised in the participating organisations for the first wave of 'trainers' facilitated by project team members. This helped to progress the cascade of the cultivating compassion activities and to explore alternative sources of embedded organisational support for the 'trainers' to promote sustainability as the project team withdrew.

\section{Evaluation of the toolkit}

Barac et al. (2014) highlighted the importance of evaluation of the design of toolkits and the evaluation of their implementation. Train-the-trainer workshops were evaluated using a questionnaire (see Appendix 2) which captured the views of participants on the day $(N=81)$ resulting from seven workshops. Data were also collected through hour-long evaluation focus groups in two of the three organisations, with groups of three and four participants; and through individual semi-structured interviews in all three organisations $(N=11)$. The interviews explored the participants' experiences of using the toolkit resources and on their cascading of the resource within their organisation in order to 'cultivate compassion' (Appendix 3 ). This evaluation enabled an exploration of issues pertinent to participants who used and cascaded the toolkit. Using focus groups and interviews allowed for detailed explanations and illustrations to be given (Polit and Beck 2012) on organisational context, experience of training sessions, and choice and experience of using toolkit resources. Semi-structured interviews were used instead of focus groups where individuals preferred this option. In addition, the three project organisational leads were interviewed regarding their thoughts about the strengths and weaknesses of the project and three attendees from the compassion workshops were interviewed about the impact of the workshop on their expression of compassion in practice. 


\section{Analysis}

The qualitative data from focus groups and semi-structured interviews were analysed alongside field notes and transcriptions of digital audio recordings. Field notes taken during the focus groups provided context for discussion and highlighted relational dynamics that may have influenced the thread of discussion that audio tape is unable to convey (Bloor et al. 2001). Thematic analysis was used according to the approach by Braun and Clarke (2006). Thematic analysis is a systematic and rigorous inductive method of analysis involving identifying and reporting themes within data. It invites the researcher to engage in reflexive awareness in order to validate the discovery of the emergence of patterns within participants' own accounts. Alongside this thematic analysis, the data from the workshop evaluation questionnaires were numerically weighted on a Likert scale and questions inviting a yes /no response and open comments were thematically analysed.

\section{Findings and discussion}

The findings provided insight into the design, value, and utility of the Cultivating Compassion toolkit. These findings are therefore presented as three parts: Part 1 comprises a table evaluating the final version of the Cultivating Compassion toolkit (Table 2); Part 2 provides the evaluations of attendees from the first train-the-trainer workshops; and Part 3 provides the focus group and interview data relating to experiences of implementing the toolkit.

\section{Part 1: The design of the toolkit}

The toolkit was made publically available on a WordPress site (http://www.cultivatingcompassionatecare.wordpress.co) and contained an indicative reading list of a range of sources of literature on compassion for health and social care students, and for those wishing to explore compassionate health care practices further. The list included government and professional documents, and literature on areas like mindfulness, selfcompassion, and compassionate leadership in healthcare organisations. There was a selection of quotations relating to compassion, web site addresses linking to various compassion national networks, and a mindfulness site with recordings from one minute to twenty minutes for staff to use at work in their breaks. The site also contained 'seek and celebrate', 'compassion pledge' activities and digital stories, and the 'compassion indicator' menu. All resources were supported with 'how to use' activity cards that outlined various activities for each resource ranging from five to forty-five minutes in length to encourage a 'pick and mix' approach for trainers to customise their own compassion training session to fit their organisation and clinical department. The site also contained various social media links including a Twitter feed, a Facebook site, and a blogging facility to encourage users to share their experiences of using the activities, see web site (above) and Table 2. 
Table 2: Compassion Indicator themes and sample indicators

\begin{tabular}{|c|c|}
\hline The Tool Kit Platform & The web site content management system \\
\hline $\begin{array}{l}\text { Using WordPress to 'host' the toolkit, provided an ideal platform for realising the } \\
\text { project team philosophy of appreciative inquiry through ease of access by a web } \\
\text { link, enhancing communication and ownership as resources were co designed } \\
\text { and enabling implementation of the compassion activities in different workplace } \\
\text { contexts through flexible, timed, variable activities. }\end{array}$ & $\begin{array}{l}\text { Ease of Access: The resources could be accessed by anyone by using a PC, } \\
\text { laptop, tablet device or smart phone in a variety of settings assuming Wi-Fi } \\
\text { present. No password was required. } \\
\text { Communication: Developing a discursive, inclusive online community that } \\
\text { could be supported through social media, for example, blogging, Twitter and } \\
\text { Facebook, was ideal for overcoming perceived difficulties in reaching a } \\
\text { geographically dispersed healthcare workforce, and managing support and } \\
\text { communication with trainers, compassion leads, and staff in geographically } \\
\text { disparate health care organisations. } \\
\text { Ownership: Resources developed by staff in the participating organisations } \\
\text { could be easily uploaded onto the site which aimed to encourage a sense of } \\
\text { ownership of the resources, and also meant that the toolkit was organic and } \\
\text { resources grew over the project timeline. } \\
\text { Adaptability: Users could approach the WordPress toolkit site with a 'pick and } \\
\text { mix' approach to the resources. This allowed for a responsiveness to the } \\
\text { individual culture of the organisations involved, differing context in which the } \\
\text { toolkit may be used and the facility to use resources for 'bite sized chunks' } \\
\text { allowing for spontaneous training opportunities with individuals or small groups } \\
\text { in clinical practice as well as formalised larger workshop style groups. }\end{array}$ \\
\hline Mindfulness & 'How to use' Activity Cards \\
\hline $\begin{array}{l}\text { Four short mindfulness tapes were included to support the concept of self- } \\
\text { compassion. These were between one and five minutes long to facilitate taking a } \\
\text { short time out to re-centre the self within a busy working life. These recordings } \\
\text { could be downloaded onto a smart phone for easy access. The meditation tapes } \\
\text { had been purchased by a partner organisation who gained permission from the } \\
\text { company to also use them on the WordPress site. Web links to free access } \\
\text { mindfulness resources on Professor Paul Gilbert's compassion mind training } \\
\text { foundation site were also provided. }\end{array}$ & $\begin{array}{l}\text { The 'how to use' activity cards enabled the toolkit to be operationalised in the } \\
\text { workplace. They provided a step-by-step guide on how to use the tools in a } \\
\text { range of settings, differing group sizes, and time frames ranging five minutes to } \\
\text { three hours. Each card contained two to four activities for all resources in the } \\
\text { Toolkit. The idea for the card format came from an online teacher training } \\
\text { programme housed in the Centre for Learning and Teaching in one of the } \\
\text { participating universities. Activity cards were designed to offer a range of short, } \\
\text { practical, engaging activities in a 'pick and mix' style. }\end{array}$ \\
\hline
\end{tabular}




\section{'Seek and Celebrate'}

Reflecting the principles of appreciative inquiry, an activity was developed to recognise existing compassionate practice in the workplace. The idea of an 'ice breaker' activity - where staff were encouraged to identify an example of an act of kindness they had witnessed in the last week - was used. This activity created a positive workshop climate through highlighting compassionate people with whom they worked.

NB. This discussion could be built upon through an activity using the compassion indicators exploring the value, conditions for, prevalence of, and factors facilitating compassion indicators.

\section{Compassion Pledges}

The pledge activity, at the end of the compassion workshop, allowed individuals or teams to make a personal commitment for change in the workplace (or themselves) which would enhance compassion. For example 'I pledge that I will make more time for listening to patients and getting to know them better'. This idea arose from the NHS 'Change Day' 4 March 2014 where a national web site was set up with examples of pledges. The aim of the compassion pledges was to empower the participants to affect a compassion change management in their organisation

\section{Compassion Indicators}

A compassion indicator menu of 65 compassion indicators was generated with staff in participating organisations The indicators are listed in nine thematic

clusters e.g. 'self-compassion', 'compassion towards others' (Table 1). 'How to use' cards provided activities that could be used with the indicators in different ways.

\section{Sample 'Activity Card'}

\section{Celebrating Compassion (10 - 15 mins)}

This can be used as the icebreaker in a Cultivating Compassion Workshop.

'Think about an act of kindness that you have observed this week.'

Share in groups of 3-4 people from mixed professional / workplace backgrounds.

Discuss:

- The potential impact on the patient;

- Could this kindness have a wider impact than that individual?

- How did it make you feel?

- Celebrate what we are already doing well.

\section{Digital Stories}

Digital stories were designed for the toolkit to stimulate imaginative interpretation and critical reflection on practice (Rolfe and Gardner 2014) and to act as a trigger for discussions on the meaning of compassion in everyday practice. Five digital stories were developed in the participating organisations. These became three minute YouTube clips supported with a 'how to use' activity card that explained the context of the story, and provided a series of cues to generate discussion following viewing.

\section{Sample 'Activity Card'}

\section{Using cards of compassion indicators (20 mins)}

Cut up compassion indicator statements into cards and provide a pile for each group.

Ask the group to look at the cards and pick up one, and discuss in threes.

- When did you last see this happen?

- When was there an opportunity for this to happen?

- Where could this happen more? 


\section{Part 2: The workshop attendee evaluations of the toolkit}

The following findings refer to evaluations from the first seven of the train-the-trainer workshops $(N=$ 81). The findings indicate that workshop attendees experienced a significant shift in their understanding about self-compassion and compassion towards others, and that they found all the resources useful but did express ambivalence towards the use of social media streaming through the toolkit site.

The workshop evaluations indicate an enhanced awareness of cultivating self-compassion, and how to cultivate compassion for others including their team. This demonstrates a shift in awareness gained from the workshop regarding the need to value, not only their own wellbeing, but the wellbeing of their team which is also supported in the interview data. Participants felt confident to cascade the toolkit activities, most favouring small group and one-to-one activities. Those who lacked confidence, stated the need for more preparation time and support from their manager, more practice with the activities, and the need to buddy another trainer first. All the toolkit resources were identified as useable in the workplace, demonstrating the universality of the toolkit. The six most popular resources were: seek and celebrate, digital stories, compassion pledges, discussion based on compassion indicators, and having a compassion notice board in their department containing 'quotes of the week' and observed acts of compassion by patients, visitors, and staff.

Most responses to Question 3 (whether they would access the toolkit site after the workshop) were positive, with participants saying they were confident to use the site or could imagine themselves using the toolkit site. Reasons for potentially not using the site were anxiety regarding the reliability of the NHS Internet connection, and a need to browse the site more to build confidence. The workshop attendees had their interest stimulated in the following thematic areas: to recognise and celebrate what is already happening in their workplace, recognise a need to accommodate for time to reflect during the working day on self-compassion, and compassion towards the team and others in their sphere of care. They recognised the need to take personal responsibility to enact being kinder towards themselves, recognising and overtly valuing the good practices of others, and to be more mindful towards their relationships with patients. They identified ideas for use of the toolkit resources in their workplace teams.

There was an intention by the project team to create a community of practice across the three NHS partner organisations through social media, however the attendees did not take this up. In response to Question 4, only half the group were confident with the idea of using social media associated with the toolkit. This reflected an ambivalence towards social media in the group. Comments ranged from being unfamiliar with Twitter, Facebook and blogging, to consciously not using social media or disliking these forms of social media. They also identified technical problems that would dissuade them, such as internet connection problems in the Trust, not possessing a smart phone, and practical issues around time and not wishing to spend more time using a computer.

Half of the group wrote a compassion pledge, many of which reflected a concern to acknowledge colleagues' good practice, such as: 'I will make sure I highlight when I notice someone being compassionate and comment on this to the person involved' and, '[t]o thank all the staff on a shift for their good work if I am shift leading'. They also recognised the importance of their own wellbeing, such as: '[p]at myself on the back more', and compassionate behaviour towards patients such as: '[t]o use the patient's name and not their bed number', and '[t]o be more open with patients and make sure they understand what's going on with their care'. There were several strategic pledges such as: '[t]o keep this visible in the workplace using posters, notice boards, compassion quotes', and '[t]o discuss with my manager how we can use this in my department and take it forward'. These pledges were not explored further by the research team, however the interviews and focus group provided evidence of many compassion pledges being acted out in practice. Not all attendees were happy to write a compassionate pledge, with one attendee expressing cynicism at the corporate tone of being asked to make a compassion pledge and associated perception of 'forcing' compassion. Whilst only one comment, the project team experienced similar comments at the initial launch of the project regarding compassion values espoused and lived out by NHS senior management in contrast to the expectations of the staff, although this perception changed when the project team changed the title of the project from 'compassion awareness' to 'cultivating compassion'. The shift in focus at the start of 
the project improved staff perceptions from having their understanding of compassion questioned to appreciating what was already working well in clinical areas, and how best to enhance compassionate practice.

\section{Part 3: The participant value and use of the toolkit resources}

The final set of data arises from the focus groups and interview data with trainers, workshop attendees, and organisational leads, and it revealed the value and use of the toolkit resource and the leadership factors influencing its implementation.

\section{Value of the toolkit resources}

Participants expressed a belief that compassion was already evident within health care practice, although feedback suggested that exposure to a cultivating compassion toolkit raised awareness of the breadth of compassion, such as the many different acts of kindness and ethical approaches involved in working together and caring together. The multi-professional participation in the train-thetrainer workshops and digital stories raised an awareness of collegiality in cultivating compassionate practice.

I felt on the day [train-the-trainer workshop] there was no hierarchy. Everyone felt they were on an equal footing. It really felt like anyone was invited to be involved and it didn't matter who you were or what you were in the organisation (professional development role).

The participants expressed recognition of the value of the toolkit, viewing it as a 'fantastic resource' which gave them the confidence to experiment with differing approaches to positive discourse on compassion with colleagues:

When people aren't confident teachers, the [activity] cards can give you options so you can pick an exercise that feels comfortable for you, so if an exercise doesn't feel right you can try another (practice educator).

\section{Using the toolkit resources}

The digital stories and 'seek and celebrate' activity cards were found to be easiest to use by almost all the participants.

The [activity] cards were brilliant (ward sister).

Despite initial concerns expressed at the train-the-trainer workshop, the participants found the online toolkit easily accessible, particularly the digital stories, and used them in a variety of contexts such as formalised workshops or as impromptu teaching using an iPad. They were able to adapt, if online access was not possible, by changing to activity cards to generate a discussion on compassion.

Participants had initial concerns that their busy colleagues would not respond well to a discourse on compassion, and felt it would be 'just too embarrassing' and were delighted when colleagues indicated they wanted training.

I literally passed on a mini version of the train-the-trainer day to a group of people in our team who weren't the most interested in it and they genuinely felt uplifted by the whole chat (ward sister).

The positive response of their colleagues gave participants the confidence to continue cascading the toolkit activities in their workplace.

What I have taken away the most from the whole project is finding it easier to talk to people about compassionate care, feeling more confident to talk about compassionate care and realise 'yes you can' (practice development role). 


\section{The need for leadership support to realise the toolkit activities}

The toolkit was designed to be used in the workplace and reflect the complexity of organisations such as the variety of disciplines as reflected in the digital stories, the inclusion of mindfulness, and emotional touchstone activities that particularly appealed to staff working in mental health. The success of cascading the toolkit differed between the organisations involved, and this was explained through the level of engagement by senior staff in the participating organisations. There were creative approaches to managing the cascading of activity, such as one organisation applying a strategic model. This involved the training team exploring all the training and development opportunities they delivered to identify where they could 'slot in' the toolkit activities. In contrast, participants implementing compassion activities as an individual, rather than as a member of a training team, highlighted the need to gain the views of their colleagues as to what activities they would feel comfortable with to engender a discourse on compassion. It was also highlighted that senior management support was essential to give the trainer the confidence to implement toolkit activities within an organisation due to the time required, with development activity timetabled into formalised mandatory training. With the use of the toolkit falling outside the official training schedule, it was felt permission was needed to engage in this novel activity. In one department where senior management valued the activity, this led to creative discourse amongst the team and adoption of an idea from social media of using ' 100 days of happiness' and a notice board in the department to identify acts of kindness by staff, patients, and carers. This group also introduced mindfulness before meetings, and sourced a quiet reflective space for staff. What emerged in these creative discussions about using the toolkit was that participant confidence to 'go ahead' and realise new ways of working was highly dependent on the level of leadership support within their organisation.

\section{Limitations}

The main limitation of this project was time. The ability to capture data once the project moved from the second wave of trainers was problematic as the one-year project timeline had come to an end at this stage. This means that the impact on the wider organisation and care delivery has not been possible to evidence. Levine et al. (2007) found evaluation of the use of their toolkit difficult because, as the use of the toolkit cascades through an organization, it becomes increasingly difficult to identify users and the informal ways in which the toolkit is used in clinical practice, particularly when using self-report evaluation measures.

\section{Conclusions}

The project team set out to develop an evidence-based toolkit to cascade cultivating compassion activities through a train-the-trainer approach within three NHS organisations. What was unique about the toolkit was that it was developed and evaluated using appreciative inquiry, and participants comprised a wide range of healthcare and support staff. The content of the compassion digital stories and compassion indicators were a reflection of the differing and shared perspectives of health care roles in the three NHS organisations, ensuring wide appeal and meaning-making for those working in mental health and acute hospital healthcare environments, engendering inter-professional learning for those involved. It was originally intended that the compassion indicators could be used as an evaluative tool to measure organisational values before and after the project as in the Dewar, Pullin, and Tocheris (2011) study. However, it took the lifetime of the project to develop the compassion indicator set. They were used successfully in the project as an activity to stimulate a discussion on the presence and absence of compassionate behaviour in the workplace and what factors might hinder and facilitate its expression. Further research is needed to take these forward as intended.

Early evaluative feedback from the first and second wave of train-the-trainer workshops and compassion indicator focus groups facilitated changes to toolkit design, and as such enabled the toolkit materials to meet the demands of a busy workforce with rationed time for organisational training initiatives. This meant the original project intention to deliver mainly half-day workshops with some shortened activities in clinical practice was 'flipped' so that resources could be delivered in the form of a 'toolkit on the move' with 'bite sized' chunks of activity. In terms of sustainability, the toolkit 
design was flexible enough to be embedded within existing care delivery systems meetings and mandatory training programmes.

This project has demonstrated that a train-the-trainer approach can be used successfully for a toolkit of resources to cultivate compassionate practice within NHS organizations. The project identified evidence of behaviour change in response to the use of the Cultivating Compassion toolkit, and a shift in perspective towards the importance of self-compassion, compassion towards colleagues, and noticing and positively recognising acts of compassion. Using the toolkit activities positively impacted upon the values-based culture in the workplace.

This project demonstrated that a cultivating compassion toolkit, co-created with the healthcare workforce, can develop confidence in engaging in discourse on the meaning of compassionate care, and provoke a focus on self-compassion and compassion towards colleagues. The appreciative inquiry approach enabled the project team to develop cultivating compassion activities that were positively received by staff and in many instances the experience of engaging in these activities was reported as enjoyable and improved wellbeing. The 'how to use' activity cards enabled trainers to feel confident about using the resources, giving them the flexibility to choose activities they felt comfortable with and could adapt to differing training environments like workshops, embedding in existing training initiatives or using as 'toolkit on the move' in clinical practice. The project also demonstrated that senior leadership support for the implementation of the train-the-trainer approach is essential in order to cascade the toolkit throughout the organisation as, without this support, staff felt insecure and skeptical regarding the view of senior management towards the value of promoting compassionate care. This project has revealed that, if organisations wish to cultivate compassionate practices, it requires leadership to clearly articulate their values and vision for compassion and ensure these are clearly supported and integrated throughout the organisation.

The focus of this article was the acceptability and co-development of the toolkit within existing healthcare staff. We do know that the toolkit continues to be utilised by the training and development team in one organisation. In order to understand the applicability of this toolkit within higher education, and as such the future healthcare staff, we are undertaking research with undergraduate healthcare students. We need to understand whether the behavioural changes noted within this study are also seen in our undergraduate student research. It is hoped that the use of a toolkit developed by healthcare workers in a clinical setting will be seen by students as an authentic educational resource, and the benefits noted (such as increased self-compassion and team compassion) will be experienced by the undergraduate students.

\section{Acknowledgements}

We would like to extend our thanks to the project team members who assisted in designing the toolkit and implemented the project within the participating organisations. For full information on the project team involved, please see the executive summary Appreciative enquiry into the development and evaluation of a 'train the trainers' approach towards cultivating compassion: report https://www.surrey.ac.uk/fhms/research/centres/ICE/ICNE\%20Files/Executive\%20Summary\%2 0Cultivating\%20Compassion.pdf 


\section{References}

Adamson, E., Dewar, B., Donaldson, J. H., Gentleman, M., Gray, M., Horsburgh, D., ...Waugh, A. (2012) Leadership in compassionate care programme: Final report. Edinburgh: Project Report. Edinburgh Napier University/ NHS Lothian. [online] available from http://www.napier.ac.uk/research-and-innovation/research-search/outputs/leadership-incompassionate-care-programme-final-report [31 January 2017]

Atkins, P. and Parker, S. (2012) 'Understanding individual compassion in organisations: The role of appraisals and psychological flexibility'. Academy of Management Review, 37 (4), 524-526 https://doi.org/10.5465/amr.2010.0490

Barac, R., Stein, S., Bruce, B., and Barwick, M., (2014) 'Scoping review of toolkits as a knowledge translation strategy in health'. BioMed Central Medical Informatics and Decision Making, 14 (121) https://doi.org/10.1186/s12911-014-0121-7

Bloor, M., Frankland, J., Thomas, M., and Robson, K. (2001) Focus Groups in Social Research. London: Sage Publications https://doi.org/10.4135/9781849209175

Braun, V. and Clarke, V. (2006) 'Using thematic analysis in psychology'. Qualitative Research in Psychology, 3 (2), 77-101 https://doi.org/10.1191/1478088706qp063oa

Brunero, S., Lamont, S., and Coates, M. (2010) 'A review of empathy education in nursing'. Nurse Inquiry, 17 (1), 65-74 https://doi.org/10.1111/i.1440-1800.2009.00482.x

Burford, G., Hoover, E., Stapleton, L., and Harder, M.K. (2016) 'An unexpected means of embedding ethics in organizations: Preliminary findings from values-based evaluations', Sustainability, 8 (7), 612 https://doi.org/10.3390/su8070612

Carter, B. (2006) "'One expertise among many" - working appreciatively to make miracles instead of finding problems: Using appreciative inquiry as a way of reframing research', Journal of Research in Nursing, 11 (1), 48-63 https://doi.org/10.1177/1744987106056488

Cole-King, A. and Gilbert, P. (2011) 'Compassionate care: The theory and the reality'. Journal of Holistic Healthcare, 8 (3), 29-36

Cooperrider, D. (2000) 'Positive image, positive action: the affirmative base of organising'. in Appreciative Inquiry: Rethinking Human Organization toward a Positive Theory of Change. ed. by Cooperrider, D., Sorensen, P., Whitney, D., and Yaeger, T. llinois: Champagne, IL: Stipes, 29-54

Cooperrider, D., Sorensen, P., Yaeger, T., and Whitney, D. (2001) Appreciative Inquiry: An Emerging Direction for Organization Development. Champagne, IL: Stipes

Crawford, P., Brown, B., Kvangarsnes, M., and Gilbert, P. (2014) 'The design of compassionate care'. Journal of Clinical Nursing, 23 (23-24), 3589-3599 https://doi.org/10.1111/jocn.12632

Curtis, K., Gallagher, A., Ramage, C., Montgomery, J., Martin, C., Leng, J., ... and, Wrigley, M. (2017) 'Using Appreciative Inquiry to develop, implement and evaluate a multi-organisation 'Cultivating Compassion' programme for health professionals and support staff'. Journal of Research in Nursing, 22 (1-2), 150-165 https://doi.org/10.1177/1744987116681376

Curtis, K., Horton, K., and Smith, P. (2012) 'Student nurse socialisation in compassionate practice: A grounded theory study'. Nurse Education Today, 32 (7), 790-795

https://doi.org/10.1016/j.nedt.2012.04.012 
Darbyshire, P. (2014) 'Character assassination? Response to John Paley, "social psychology and the compassion deficit"'. Nurse Education Today, 34, 887-889

https://doi.org/10.1016/j.nedt.2014.03.007

Davis, D., Evans, M., Jadad, A., Perrier, L., Rath, D., Ryan, D., ... and, Zwarenstein, M. (2003) 'The case for knowledge translation: Shortening the journey from evidence to effect'. British Medical Journal, 327 (7405), 33-35 https://doi.org/10.1136/bmj.327.7405.33

Davis, D., O'Brien, M., Freemantle, N., Wolf, F., Mazmanian, P., and Taylor-Vaisey, A. (1999) 'Impact of formal medical education: Do conferences, workshops, rounds and other traditional education activities change physician behavior or health care outcomes?' Journal of American Medical Association, 282 (9), 867-874 https://doi.org/10.1001/jama.282.9.867

Dewar, B. and Christley, Y. (2013) 'A critical analysis of Compassion in Practice'. Nursing Standard, 28 (10), 46-50 https://doi.org/10.7748/ns2013.11.28.10.46.e7828

Dewar, B. and Cook, F. (2014) 'Developing compassion through a relationship centred appreciative leadership programme. Nurse Education Today, 34 (9), 1258-1264 https://doi.org/10.1016/j.nedt.2013.12.012

Dewar, B., Pullin, S., and R. Tocheris (2011) 'Valuing compassion through definition and measurement'. Nursing Management, 17 (9), 32-37 https://doi.org/10.7748/nm2011.02.17.9.32.c8301

Department of Health (2012) Compassion in Practice: Nursing, Midwifery and Care Staff. Our Vision and Strategy. London: The Stationery Office. [online] available from https://www.england.nhs.uk/wp-content/uploads/2012/12/compassion-in-practice.pdf [31 March 2017]

Department of Health (2013) Delivering High Quality, Effective, Compassionate Care: Developing the Right People with The Right Skills And The Right Values. A Mandate from the Government to Health Education England: April 2013 to March 2015. London: Department of Health [online] available from https://www.gov.uk/government/uploads/system/uploads/attachment data/file/203332/29257 2900971 Delivering Accessible.pdf [31 January 2017]

Department of Health (2015) The NHS Constitution: The NHS Belongs to All of Us. London: Department of Health [online] available from https://www.gov.uk/government/uploads/system/uploads/attachment data/file/480482/NHS Constitution WEB.pdf [31 March 2017

Epstein, R. (1999) 'Mindful practice'. Journal of American Medical Association, 282 (9), 833-839 https://doi.org/10.1001/jama.282.9.833

Firth-Cozens, J. and Cornwell, J. (2009) Enabling Compassionate Care in Acute Hospital Settings. London: King's Fund. [online] available from https://www.kingsfund.org.uk/sites/files/kf/field/field publication file/poc-enablingcompassionate-care-hospital-settings-apr09.pdf [31 January 2017]

Francis, R. (2010) Independent Inquiry into the Care Provided by Mid Staffordshire NHS Foundation Trust January 2005 - March 2009. London: The Stationery Office

Francis, R. (2013), Report of the Mid Staffordshire NHS Foundation Trust Public Inquiry. London: The Stationery Office 
Gazarian, P. (2010) ‘Digital stories: Incorporating narrative pedagogy'. Journal of Nursing Education, 49 (5), 287-290 https://doi.org/10.3928/01484834-20100115-07

Goodrich, J. and J. Cornwell (2008) Seeing the Person in the Patient. The Point of Care Review Paper. London: The King's Fund [online] available from https://www.kingsfund.org.uk/sites/files/kf/Seeing-the-person-in-the-patient-The-Point-ofCare-review-paper-Goodrich-Cornwell-Kings-Fund-December-2008 0.pdf [31 March 2017]

Hammond, S.A. (1998) The Thin Book of Appreciative Inquiry. 2nd edn. Plano, TX: Thin Book Publishing Company.

Hardy, P. and Sumner, T. (2014) Cultivating Compassion. How Digital Story Telling is Transforming Healthcare. Chichester, UK: Kingsham Press

Herbst, A., Swengros, D., and Kinney, G. (2010) 'How to teach human caring: nurse educator role in transformational learning for a large healthcare system'. Journal for Nurses in Staff Development, 26 (4), e6-e11 https://doi.org/10.1097/nnd.0b013e3181b1ba55

Irons, C. (2013) 'The science of compassion: Evolutionary, neurophysiological and physiological perspectives'. Journal of Holistic Healthcare, 10 (3), 10-15

Kitzinger, J. (1995) 'Qualitative research: Introducing focus groups'. British Medical Journal, 311 (7000), 299-302 https://doi.org/10.1136/bmj.311.7000.299

Lambert, J. (2013) Digital Storytelling: Capturing Lives, Creating Community. 4th edn. New York, NY: Routledge

Levine, S., Brett, B., Robinson, B., Stratos, G., Lascher, S., Granville,, L. Goodwin, S., ... and Barry, P. (2007) 'Practising physician education in geriatrics: Lessons learned from a train-thetrainer model'. The Journal of American Geriatrics Society, 55 (8), 1281-1286 https://doi.org/10.1111/j.1532-5415.2007.01205.x

Maben, J., Peccei, R., Adams, M., Robert, G., Richardson, A. Murrells, T., and Morrow, E. (2012) Exploring the Relationship between Patients' Experiences of Care and the Influence of Staff Motivation, Affect and Wellbeing. Final Report. National Institute for Health Research. London: HMSO. [online] available from http://www.netscc.ac.uk/hsdr/files/project/SDO FR 08-1819-213 V01.pdf [31 January 2017]

McClelland, J.W., Irving, L.M., Mitchell, R.E., Bearon, L.B., and Webber, K.H. (2002) ‘Extending the reach of nutrition education for older adults: Feasibility of a train-the-trainer approach in congregate nutrition sites'. Journal of Nutrition Education and Behavior, 34 (1), S48-S52 https://doi.org/10.1016/S1499-4046(06)60311-4

Mullen, K. (2009) Patients not Numbers. People not Statistics. 2nd edn. Harrow, UK: Patients Association. [online] available from https://www.patients-association.org.uk/wpcontent/uploads/2014/08/Patient-Stories-2009.pdf [31 January 2017]

Neff, K D. (2003) 'The development and validation of a scale to measure self-compassion'. Self and Identity, 2 (3), 223-250 https://doi.org/10.1080/15298860309027

Neff, K.D. and Pommier, E. (2013) 'The relationship between self-compassion and other-focused concern among college undergraduates, community adults and practicing mediators'. Self and Identity, 12 (2), 160-176 https://doi.org/10.1080/15298868.2011.649546

Paley, J. (2014) 'Cognition and the compassion deficit: The social psychology of helping behavior in nursing'. Nursing Philosophy, 15 (4), 274-287 https://doi.org/10.1111/nup.12047 
Pearcey, P. (2007) 'Tasks and routines in 21st Century nursing: Student nurses' perceptions'. British Journal of Nursing, 16 (5), 296-300 https://doi.org/10.12968/bjon.2007.16.5.23007

Polit, D. and C. Beck (2012) Nursing Research: Generating and Assessing Evidence for Nursing Practice. 9th edn. Philadelphia, PA: Lippincott Williams and Wilkins

Raab, K. (2014) 'Mindfulness, self-compassion, and empathy among health care professionals: A review of the literature'. Journal of Health Care Chaplaincy, 20 (3), 95-108 https://doi.org/10.1080/08854726.2014.913876

Richardson, C., Percy, M., and Hughes, J. (2015) 'Nursing therapeutics: teaching student nurses care, compassion and empathy'. Nurse Education Today, 35 (5), e1-e5 https://doi.org/10.1016/j.nedt.2015.01.016

van der Cingel, M. (2014) 'Compassion: The missing link in quality of care'. Nurse Education Today, 34 (9), 1253-1257 https://doi.org/10.1016/j.nedt.2014.04.003

von Dietze, E. and Orb, A. (2000) 'Compassionate care: A moral dimension of nursing' Nursing Inquiry, 7 (3), 166-174 https://doi.org/10.1046/.1440-1800.2000.00065.x

Weng, H., Fox, A., Shackman, A., Stolda, D., Caldwell, J., Olson, M., ... and Davidson, R. (2013) 'Compassion training alters altruism and neural responses to suffering'. Psychological Sciences, 24 (7), 1171-1180 https://doi.org/10.1177/0956797612469537

White, L. (2014) 'Mindfulness in nursing: An evolutionary concept analysis'. Journal of Advanced Nursing, 70 (2), 282-294 https://doi.org/10.1111/jan.12182

Youngson, R. (2011) 'Compassion in Healthcare'. Journal of Holistic Healthcare, 8 (3), 6-9 


\section{Appendix 1: 'Train-the-trainer' workshop}

\begin{tabular}{|c|c|c|}
\hline \multicolumn{3}{|c|}{ Workshop } \\
\hline \multirow{6}{*}{ 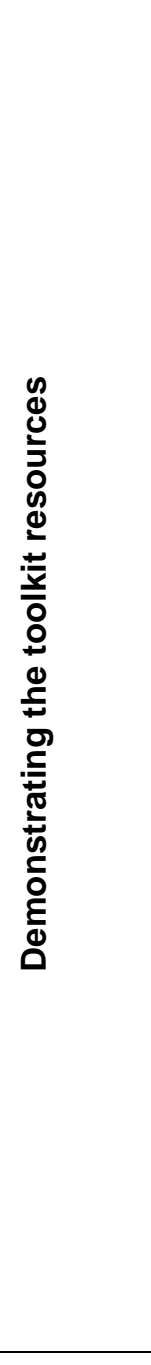 } & $\begin{array}{l}\text { Introduction - self, attendees and explain the } \\
\text { format for the morning }\end{array}$ & $\begin{array}{l}\text { Facilitator and group - create a } \\
\text { welcoming environment }\end{array}$ \\
\hline & $\begin{array}{l}\text { Compassion Indicators } \\
\text { Gather up several indicator statements and } \\
\text { discuss them in groups of three. Rank between } \\
\text { you the top three indicators from those you } \\
\text { have. Discuss what helps you to sustain them. } \\
\text { Resources - cut up card copies of the } \\
\text { compassion indicators, split equally amongst } \\
\text { the groups. E.g.: If there are fifteen in a group } \\
\text { they could have thirteen indicators for each } \\
\text { group of three }\end{array}$ & $\begin{array}{l}\text { This helps to build up the groups from } \\
\text { the beginning. The choice of indicators } \\
\text { can be a way of introducing the self to } \\
\text { each other in the group. This is also } \\
\text { about building resilience. How do they } \\
\text { look after the self? }\end{array}$ \\
\hline & $\begin{array}{l}\text { Why has compassion become a political } \\
\text { issue? } \\
\text { The way forward from the Francis Report. } \\
\text { What initiatives are taking place in this } \\
\text { trust/practice? }\end{array}$ & $\begin{array}{l}\text { Contextualising compassion in } \\
\text { healthcare. } \\
\text { How do organisations support } \\
\text { compassionate healthcare? Identifying } \\
\text { what you do well. E.g. Schwarz rounds, } \\
\text { 'my name is'. This is about building a } \\
\text { story of positive action }\end{array}$ \\
\hline & $\begin{array}{l}\text { Digital stories } \\
2 \text { examples and discussion }\end{array}$ & $\begin{array}{l}\text { Building on first exercise, discovering } \\
\text { shared values }\end{array}$ \\
\hline & $\begin{array}{l}\text { Making a compassion pledge relating to your } \\
\text { role as trainer } \\
\text { Resource - Return to compassion indicators }\end{array}$ & $\begin{array}{l}\text { Compassion pledge examples } \\
\text { Team relationships respecting and } \\
\text { valuing each other personally and } \\
\text { professionally }\end{array}$ \\
\hline & $\begin{array}{l}\text { A compassion story, examples from practice } \\
\text { five volunteers - Followed by discussion }\end{array}$ & $\begin{array}{l}\text { Discovering the value of sharing stories } \\
\text { and feeling confident in 'talking about } \\
\text { compassion' to others }\end{array}$ \\
\hline \multicolumn{3}{|c|}{ Lunch } \\
\hline \multirow{4}{*}{ 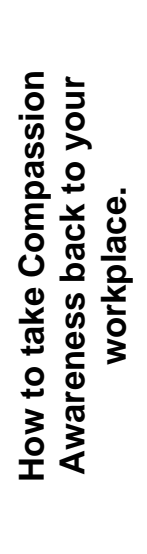 } & $\begin{array}{l}\text { Toolkit exploration - sharing ideas } \\
\text { Discuss amongst themselves how they could } \\
\text { envisage using the toolkit resources- share } \\
\text { ideas }\end{array}$ & $\begin{array}{l}\text { Identify what do they want to use? } \\
\text { What appeals, any concerns? How } \\
\text { could these be addressed? }\end{array}$ \\
\hline & $\begin{array}{l}\text { Communication and support } \\
\text { Blogging, Twitter to create your own } \\
\text { compassion circle }\end{array}$ & $\begin{array}{l}\text { What will they get from blogs/Twitter - } \\
\text { Compassion Circles facilitated in their } \\
\text { organisation }\end{array}$ \\
\hline & Using the toolkit (how to use activity cards) & \\
\hline & $\begin{array}{l}\text { Discussing in small groups how they could use } \\
\text { the activity cards in workshops / in practice. }\end{array}$ & $\begin{array}{l}\text { Building confidence in the usage of the } \\
\text { toolkit. Seeing possibilities. Talking } \\
\text { about how it can be introduced }\end{array}$ \\
\hline
\end{tabular}




\section{Appendix 2: Evaluation of the Cultivating Compassion workshop}

1. How would you rate the following:

\begin{tabular}{|c|l|l|l|l|}
\hline The Venue & Very good - 4 & Good - 3 & Satisfactory - 2 & Poor - 1 \\
\hline $\begin{array}{l}\text { How did you find } \\
\text { the physical } \\
\text { environment of } \\
\text { the workshop? }\end{array}$ & & & & \\
\hline Content of workshop & Very good - 4 & Good - 3 & Satisfactory - 2 & Poor - 1 \\
\hline $\begin{array}{l}\text { Sufficiently } \\
\text { thought } \\
\text { provoking? }\end{array}$ & & & & \\
\hline $\begin{array}{l}\text { How well was it } \\
\text { delivered? }\end{array}$ & & & & \\
\hline $\begin{array}{l}\text { How do you rate } \\
\text { the resources } \\
\text { you have seen } \\
\text { today in the 'tool } \\
\text { kit' }\end{array}$ & & & & \\
\hline $\begin{array}{l}\text { workshop } \\
\text { enhance your } \\
\text { awareness of } \\
\text { how to } \\
\text { cultivate } \\
\text { compassion - }\end{array}$ & Very well - 4 & Better - 3 & The same - 2 & Not at all - 1 \\
\hline $\begin{array}{l}\text { For the Self } \\
\text { For the Team / } \\
\text { others }\end{array}$ & & & & \\
\hline
\end{tabular}

2. Do you now think that you could share the 'toolkit' activities in your own workplace in a workshop? Yes / No In small groups in the workplace? Yes/No In 1:1's in the workplace? Yes/No (please circle)

If you circled Yes, please give example(s) of what particular 'toolkit' activities you can envisage using

If No, state why and what assistance you think you need to support this

3. Do you feel relatively confident accessing the tool kit web site following this workshop? Yes / No (please circle)

If Yes, what kinds of things have attracted your interest?

If No, please suggest what might help you to feel more confident?

4. Do you think you may use/ access the following cultivating compassion social media please circle Yes or No

- Tool kit - blog facility Yes/No

- Twitter Yes/No

- Facebook Yes/No

If you don't think you will use these, could you please state why?

5. What would you have liked in this workshop that you didn't experience

6. Have you decided to make a compassion pledge following today? If Yes, could you please write down what that pledge would be? 


\section{Appendix 3: Interview schedule}

Sample of areas explored in evaluation focus groups and interviews

Areas to be explored in the focus group and interviews:

Questions re demographics

Where do you work and what is your role in the organisation?

Your experience of using the tool kit?

Cue:

In what ways have you delivered the compassion training in your organisation? workshops, 1:1, small groups

What tools have you found most useful from the 'toolkit'?/ What worked, what didn't?

- Digital stories

- Values indicators

- Mindfulness

- Compassion pledges and the other tools

- Activity cards - were they useful for the tools, which ones worked, which ones didn't

Have you seen any evidence of people who attended your sessions using anything from the toolkit?

How do you think your sessions were received?

\section{Questions around fit}

Cue:-

What is your view about the train-the-trainer approach and how it works in your organisation? - Give examples

What is your view of the 'train-the-trainer model' for a topic like compassion?

What support has been given and needed?

What has been your experience of trying to sustain practice development against the backdrop of the winter pressures?

What is your feeling about this?

\section{Looking at the project}

Cue:-

How, if at all, would you say the project has impacted on your area of practice?

Your view of compassion in care

Cues:-

How do you think compassionate care can be developed?

How do you feel about talking to practitioners about compassion?

How do you think practitioners perceive 'compassion training'?

Has being involved in this project had an impact on you?

If so in what way(s)? 